\title{
Measuring populism across nations: testing for measurement invariance of an inventory of populist attitudes
}

\author{
Wettstein, Martin ; Schulz, Anne ; Steenbergen, Marco R ; Schemer, Christian ; Müller, Philipp ; Wirz,
}

Dominique S ; Wirth, Werner

\begin{abstract}
The rising voter support for populist parties in Western Democracies in recent years has incited academic interest in populist voters and attitudes connected to the voting propensity of populist actors. In line of this research, numerous scales to measure populist attitudes among voters have been proposed. In most cases, however, the measurement of populist attitudes was tailored to specific countries and its applicability to crossnational research on populism was not assessed. This article uses a cross-national survey to assess the measurement invariance, reliability, and validity of a deductively developed inventory for populist attitudes. The findings suggest that there is a common attitudinal base to left- and right-wing populism which may be measured reliably and invariantly across nations.
\end{abstract}

DOI: https://doi.org/10.1093/ijpor/edz018

Posted at the Zurich Open Repository and Archive, University of Zurich

ZORA URL: https://doi.org/10.5167/uzh-185164

Journal Article

Submitted Version

Originally published at:

Wettstein, Martin; Schulz, Anne; Steenbergen, Marco R; Schemer, Christian; Müller, Philipp; Wirz, Dominique S; Wirth, Werner (2020). Measuring populism across nations: testing for measurement invariance of an inventory of populist attitudes. International Journal of Public Opinion Research, 32(2):284-305.

DOI: https://doi.org/10.1093/ijpor/edz018 


\begin{abstract}
The rising voter support for populist parties in Western Democracies in recent years has incited academic interest in populist voters and attitudes connected to the voting propensity of populist actors. In line of this research, numerous scales to measure populist attitudes among voters have been proposed. In most cases, however, the measurement of populist attitudes was tailored to specific countries and its applicability to cross-national research on populism was not assessed. This paper uses a cross-national survey to assess the measurement invariance, reliability, and validity of a deductively developed inventory for populist attitudes. The findings suggest that there is a common attitudinal base to left- and right-wing populism which may be measured reliably and invariantly across nations.
\end{abstract}

Keywords: Populism; Measurement Invariance; Attitudes; Voting Intention 


\section{Measuring Populism across Nations: Testing for Measurement Invariance of an Inventory of Populist Attitudes.}

A populist Zeitgeist has enveloped much of Europe and the American continent, as evidenced by the electoral successes of populist parties over the past decade as well as populist causes such as Brexit (van Kessel, 2015; Mudde, 2004; Rooduijn, de Lange \& van der Brug, 2014). Against this backdrop, scholars of political psychology are now asking to what extent the public has come to embrace populism and how this varies across nations (e.g., Rooduijn, 2017; van Hauwaert \& van Kessel 2017). Since populism, in reality, does not occur as an abstract concept but is associated with quite different political actors across time and space (Taggart, 2000; Hawkins \& Rovira Kaltwasser, 2017), the cross-cultural measurement of populist attitudes is non-trivial. In the past, many scales for the measurement of populist attitudes have been proposed (e.g., Akkerman, Mudde \& Zaslove, 2014; Littvay \& Castanho Silva, 2016; Oliver \& Rahn, 2016; van Hauwaert \& van Kessel 2017), most of which have been tailored to the political reality in single countries. Although some scales have been used in multinational designs, the degree to which measurements in different national contexts are comparable is yet undetermined.

If scholars are to understand the international appeal of populism and the support for these movements, it is essential to develop measurement instruments that are deduced from a definition of populism which is applicable across time and space. Furthermore, to compare correlations of populist attitudes with other concepts across nations, measurement invariance has to be established (Davidov, 2009). Recently, Schulz and colleagues (2017) proposed a deductively developed inventory of populist attitudes (IPA) which is based on a minimal and consensual definition of populist ideology. However, the scale has only been tested in one country and the degree to which it exhibits cross-national measurement invariance is unknown. 
In this study, we apply this IPA in a cross-national survey in eleven countries (i.e.: Austria, Bulgaria, France, Germany, Italy, the Netherlands, Poland, Sweden, Switzerland, the United Kingdom, and the United States) to systematically test its measurement invariance using multi-group confirmatory factor analysis (MGCFA; Steenkamp \& Baumgartner, 1998). In addition, we use correlational analyses with political orientations and voting intentions to assess its criterion validity.

\section{Review of measurement approaches to populist attitudes}

While the public understanding of the term 'populist' is strongly debated, a scientific consensus has been reached to the extent that there is a minimal definition of populism which is applicable to democracies across time and space (for an overview see van Kessel, 2015). This definition identifies populism as a thin-centered ideology that is composed of three core ideas. It sees society ultimately divided into a vicious elite and a homogeneous virtuous people and demands the power to be with the latter in order to ensure popular sovereignty (Taggart, 2000; Mudde, 2004).

In reality, this thin populist ideology is enriched with left- or right-wing ideology, charismatic populist leaders, certain styles of communication, and concrete policy demands (Mudde, 2004). In addition, populist actors are often part of the financial and political elite themselves, and need to rhetorically solve the dilemma of being an anti-elitist high-ranking politician (Albertazzi \& McDonnell, 2008). Also, populist actors do not always fight for direct democracy, but may choose to directly represent the will of the people which they claim to have internalized (Barr, 2009). Consequentially, populist actors differ strongly from each other, depending on their national context and orientation (Taggart, 2000). Nevertheless, they all share an ideological core which is expressed in the minimal definition. 
Until recently, this definition of populism was mainly used to describe political actors and discourse (e.g. Ernst et al., 2017; Manucci \& Weber, 2017). The core elements of its thin ideology may, however, also correspond with individual-level attitudes. People might hold that the political elite is corrupt and vicious, perceive the people to be a homogeneous and virtuous group, and favor the notion that this people should exercise full and unrestricted sovereignty. Populist attitudes thus represent a set of political ideas (Hawkins \& Rovira Kaltwasser, 2017), that may be tapped with adequate survey questions.

In an influential study on populist attitudes, Hawkins et al. (2012) used an extensive survey to identify possible items for a unidimensional scale to assess populist attitudes in the public. Their work was extended by Akkerman et al. (2014) who used the minimal definition of populism to refine the scale, selecting items representing the "sovereignty of the people, opposition to the elite, and the Manichean division between good and evil." (Akkerman et al., 2014: 1331). Others have sought to measure populism as a multi-dimensional concept and clearly distinguish it from other ideological measurements and making sure to specify different components of the concept separately (Stanley, 2011; Littvay \& Castanho Silva, 2016; Schulz et al. 2017). In some cases, these measurements have been extended with exclusionist (Hameleers et al., 2017) and right-wing-radical (Rooduijn, 2014) notions to better capture the political reality of current populist movements.

Regardless of the measurement approach and underlying assumptions, most current scales agree with the minimal definition and include a Manichean perspective with antiestablishment notion and a positive attitude toward the people, as well as a demand for more popular sovereignty. Populist attitudes measured with these instruments have been successfully linked to other political ideologies (Hawkins, Riding \& Mudde, 2012), populist party preferences (Akkerman et al., 2014;), support for populist candidates (Rovira Kaltwasser \& Hawkins, 2014), political issue stances (Hawkins et al., 2012; van Hauwaert \& 
van Kessel, 2017), media preferences and perceptions (Hameleers et al., 2017; Schulz, 2018; Schulz, Wirth \& Müller, 2018), and a variety of dispositions (Spruyt, et al. 2016). Furthermore, the different measurements have been shown to discriminate populist attitudes from distinct concepts like elitism and pluralism (Akkerman, et al. 2014; Schulz et al. 2017). However, even if some scales are already used in cross-national surveys and comparative designs (van Hauwaert \& van Kessel, 2017), there is yet no scale for measuring populist attitudes for which measurement invariance across nations is established.

\section{Cross-national scale for populism}

When developing a scale for cross-national research, it is important to ensure that the scale measures the same concept in each cultural context (Davidov, 2009). Specifically, the measurement must tap into the same concept in all cultural contexts and should be statistically invariant across nations. As a minimal requirement, this means that the correlational structure of the measurement is universal. Further, if the covariation with other concepts or the absolute values are to be compared, the scale should exhibit metric or scalar measurement invariance (Davidov, 2009).

Therefore, in order to find a scale for populist attitudes, which is applicable in crosscultural research, it is preferable to follow an etic approach (Wirth \& Kolb, 2012) in which the measurement is based on the consensual definition of populist ideology which is applicable across space and time (Hawkins \& Rovira Kaltwasser, 2017). A scale developed in this approach measures the core ideology of populism, which is common to all populist movements, and is thus likely to exhibit an invariant structure across countries. At the same time, this approach abstracts from the political reality of countries where populism may be closely associated to exclusionism, right-wing extremism, workforce empowerment, or other ideologies, as it focuses on the common ground of populist movements. 
Considering measurement structure, different views regarding the dimensionality of populist attitudes have emerged. Most of the research to date applies a unidimensional conceptualization of populist attitudes (Akkerman et al., 2014; Rovira Kaltwasser \& Hawkins, 2014; Stavrakakis, et al., 2016, van Hauwaert \& van Kessel, 2017). Only recently, scholars have begun to treat populism as a multidimensional construct (Littvay \& Castanho Silva, 2016; Hameleers, et al., 2017; Rooduijn, 2014). These scholars view populism as an attitudinal syndrome consisting of different elements, which together, form a single latent idea. The benefit of this approach is that it offers a detailed view of the different elements that comprise populist attitudes. In addition, it allows researchers to pin-point eventual cultural differences caused by the political reality in individual countries by comparing the correlations and relative difficulty of sub-dimensions.

Recently, a promising multi-dimensional scale using an etic approach was presented by Schulz et al. (2017) which assesses respondents' levels of anti-elitism, support for popular sovereignty, and perception of the people (see Table 1). The first two dimensions of this inventory of populist attitudes (IPA) refer to facets of the populist ideology that were already tapped in the seminal studies on populist attitudes (Hawkins et al., 2012, Akkerman et al., 2014). The third dimension, comprising the perception of the people, was added to comply with the minimal definition of populism (Mudde, 2004).

At the moment of writing, the IPA is the only deductive and multi-dimensional full scale for populist attitudes that accounts for all dimensions of the ideology and measures populist attitudes without referencing a particular ideology (other than the populist ideology) or policy positions. As such, it is independent of political realities and can be used to assess all sorts of populism, including left-, and right-wing populism. Additionally, the IPA was shown to be statistically distinct from elitist and pluralist attitudes (Schulz et al. 2017), which are the two main counterparts to populism (Mudde, 2004). 
The IPA operationalizes populism as a second-order factor that drives three first-order factors, corresponding to the three sub-dimensions: anti-elitism, popular sovereignty, and the perception of a homogeneous and virtuous people. The first-order factors are reflected each in four indicators as illustrated in Table 1. It has been shown that the higher-order factor model outperforms unidimensional conceptualizations in terms of model fit (Schulz et al. 2017). Preceding work, however, only focuses on a single country (Switzerland). Although it was successfully applied to different countries, such as Germany (Schulz et al., 2015), France, and Great Britain (Müller et al. 2017; Wirz et al. 2018), its invariance was not explicitly assessed. In this paper, we take the IPA to a critical test by evaluating the reliability and validity of the scale in comparative research.

\section{Scale reliability}

The prime prerequisite for any scale is a reliable measurement. For instruments used in cross-national settings, this does not only mean that the scale should be reliable within each country, but that it should exhibit some degree of measurement invariance (Davidov, 2009; Jowell, 1998). If the configuration of the measurement model or the weight of its subdimensions and items varies between countries, the scale may not be assumed to measure the same concept in each case and is unfit to be used in comparative designs.

For multi-dimensional constructs, measurement invariance is conventionally tested using multi-group confirmatory factor analysis (MGCFA) which allows for the assessment of configural, metric, and scalar invariance (Davidov, 2009; Steenkamp \& Baumgartner, 1998). In this approach, parallel CFAs are done in all countries with varying degrees of restrictions to test whether the measurement model is invariant to the country. The least demanding restriction is the configuration of the model. If the same correlational structure among the items and latent variables may be imposed on the data of all countries, configural invariance is established and the scale is reliable in each individual country. 
More demanding is metric invariance, which requires that the loadings of like items and factors are invariant across all groups. Metric invariance is a necessary condition for cross-national comparisons on correlations with other constructs. If researchers aim at comparing absolute values, scalar invariance is required. This means that measurement intercepts must be identical across countries. With scalar invariance, differences in the observed item means are directly proportional to differences in the latent means.

Some researchers argue that partial invariance suffices (Byrne, Shavelson \& Muthén, 1989), meaning that only a subset of the items for each factor have to exhibit invariance in order to make cross-national comparisons. This lowers the hurdle somewhat, although ideally, the subset of invariant items should not be too small and that issues with invariance should be discussed when using the scale.

\section{Scale validity}

In addition to the reliability of a scale, it also has to be valid to be used as a measurement. This means that it should be composed of items which have the same meaning in all languages and cultural contexts and that it exhibits high criterion validity in that it should be correlated with related constructs. Here, the intention to vote for populist parties is undoubtedly the most proximal construct and has already been shown to be related to populist attitudes (van Hauwaert \& van Kessel, 2017). A valid measurement for populism should correlate positively with voting propensity for populist parties and negatively with mainstream parties.

In addition, the measurement should be linked to left-right ideology, even if the meaning of this concept itself varies cross-nationally (Piurko, Schwartz and Davidov, 2011). By now, it is well established that populism tends to attract citizens from both extremes of the political spectrum (Bakker, Rooduijn and Schumacher, 2016), although right-wing populism is more prominent in most Western European countries to date. We therefore expect to see an 
overall curvilinear relationship between the IPA and left-right orientations with lowest values in the center. Depending on the political reality in each country, however, the strength of this curvilinear relationship may be more or less pronounced.

\section{Data and Methods}

\section{Scale translation}

To ensure the validity of the instrument, we took great care in translating the items of the IPA to all languages in the survey. Translations are a key aspect of cross-national survey research and their quality influences all aspects of measurement, not least invariance (Harkness, Villar \& Edwards, 2010). We used professional translators from the contracted survey institutes for a first translation into the eight interview languages. The resulting translations were checked by an invited panel of populism scholars from each country that were asked to re-translate the items and compare the wording of each item to the aspect of the minimal definition it was aimed to capture. This was to ensure that the translations were not only semantically sound but also preserved their relationships with the latent constructs (Davidov et al., 2014; Wirth \& Kolb, 2012).

\section{Sample}

We administered the IPA in eleven countries. Using the United Nations classification scheme, our country sample includes two Eastern (Bulgaria and Poland), two Northern (Sweden and the U.K.), one Southern (Italy), and five Western European (Austria, France, Germany, the Netherlands, and Switzerland) countries, as well as the United States. Apart from being culturally diverse, the country sample also reflects variations in the success and nature of populist actors (Table 2).

Populist parties were identified using the typologies of Van Kessel (2015), Mudde (2007), and Rooduijn et al. (2014). These authors also designate the ideological character of 
populism. Note that we list no populist parties for the United States. Although the Tea Party can be considered a populist movement (Mead, 2011), it was part of a non-populist republican party in 2015. Also, the survey was done before Donald Trump and Bernie Sanders had started their populist campaigns for presidency.

The populist vote shares in our sample vary from five (U.K.) to well over 50 percent (Italy) with left-right scores spanning from far left to far right. For some countries, populism is an exclusively right-wing phenomenon (e.g., Austria and France). In others, both left- and right wing populism can be observed (e.g., Germany and the Netherlands). In two countries, we observe strong genuine populist parties (Italy and Poland) without distinctive left-right orientation. Consequently, we believe that our country sample captures the wide variety of populism in Western democracies.

Within each country, we conducted an online survey in a sample of 1'000 respondents (1’017 in Germany). Respondents were invited from existing online access panels using quotas for age, sex, and education. The samples are representative or for sex but fall short for age and education (see Online Appendix A). On the whole, our samples tended to be a bit older than the population median. The bias ranges from 7.2 months to five years. For education, the quota had to be relented in some countries due to low response rates of those with no or only primary education. This led to an overrepresentation for the groups with secondary or tertiary education. While the quotas for education were sufficiently realized in the Netherlands, the U.S., France and Germany, the samples of the remaining countries deviate from the population by 6 to 20 percent, each regarding different education categories.

The survey was conducted in all eleven countries in March 2015. It took respondents an average of around 21 minutes ( \pm 5 minutes across countries) to complete the survey. 


\section{Measures}

Populism. The IPA operationalizes populism as a second-order factor which manifests in three dimensions. Each sub-dimension is tapped using four items. Based on the minimal definition of thin populist ideology, the dimensions are anti-elitism (e.g.: "MPs in Parliament very quickly lose touch with ordinary people.”), Homogeneity of the people (e.g.: "Ordinary people are of good and honest character.") and popular sovereignty (e.g.: "The people, not the politicians, should make our most important policy decisions.") (see Table 1). All items are measured on five-point rating scales ( 1 = "strongly disagree" to 5 = "strongly agree.").

Left-Right Orientation. Respondents were asked to position themselves on the leftright spectrum on a single item: "In politics, people sometimes talk of 'left' and 'right.' Where would you place yourself on a scale ranging from 'left' to 'right?' " The scale ranges from $1=$ "left" to $11=$ "right" $(M=6.03, S D=2.60)$.

Voting Intention. We asked respondents how likely they were to vote for six to ten parties in their own country: "There are a number of parties in [country] each of which would like to get your vote. How probable is it that you will ever vote for the following parties?" The list included the populist parties as indicated in Table 2, as well as all parties with a vote share above $4 \%$ in the last election. The response scale ranges from $1=$ "not at all probable" to 5 = "very probable" (see Table 4 and Table 5 for means and standard deviations of voting intentions for populist and non-populist parties).

\section{Analysis}

\section{Invariance}

We tested the measurement model (Figure 1) in an MGCFA with each country constituting a group. Following the recommendations by Steenkamp and Baumgartner (1998), we proceeded in three steps. First, we assessed whether the factor structure was identical across our eleven countries, followed by tests of restrictions on factor loadings (slopes) and 
intercepts. This allows us to check for configural, metric, and scalar invariance, respectively. All estimations were done using the lavaan package in R (Rosseel, 2012). We used maximum likelihood estimation with Satorra-Bentler scaled test statistics, which are robust against violations of normality (Satorra \& Bentler, 2001).

While MGCFA is a useful tool for assessing measurement invariance, it is generally considered to be a conservative method (Davidov et al., 2015). Each restriction can reduce the model fit considerably, especially in datasets with large or unequal groups and unsystematic minor invariance problems (cf. Chen, 2007, p. 500). To minimize these problems, we rely on the recommendations of Chen $(2007$, p. 501). For large samples, as we have here, the recommendation is to compare the root mean squared error of approximation (RMSEA) and the comparative fit index (CFI) between restricted and unrestricted models. Any increase in the RMSEA above .015, in combination with a decrease in the CFI of .010, could indicate a lack of invariance.

In addition to the invariance analyses, we assess the reliability of the IPA and its subscales. We also regress the IPA score on the left-right orientation of the respondent as well as its square using a hierarchical linear model. This allows us to capture the hypothesized nonlinear relationship between the two variables overall and within each country. Finally, we correlate respondents' IPA scores with their intentions of voting for populist and other parties.

\section{Results}

\section{Measurement invariance}

Our first result provides support for the second-order factor model proposed by Schulz et al. (2017) when we pool all of the survey data. As can be seen in Figure 1, the subdimension linked most strongly to the overarching populism factor is the demand for popular sovereignty, followed by anti-elitism, and then by the perceived homogeneity of the people. 
The fit indices of the pooled data $(\mathrm{CFI}=.976$; $\mathrm{RMSEA}=.048)$ are well within the limits proposed by $\mathrm{Hu}$ and Bentler (1999), to wit $\mathrm{CFI} \geq .95$ and $\mathrm{RMSEA} \leq .08$. The results also point toward a three-dimensional measurement model as the fit of a one-factor model is considerably worse $(\mathrm{CFI}=.645$ and $\mathrm{RMSEA}=.184)$.

When we perform MGCFA and impose configural invariance, the fit deteriorates slightly $(\mathrm{CFI}=.975 ; \mathrm{RMSEA}=.050)$. Looking at the second-order factor model for the individual countries, we observe that it fits well in all countries, with CFI and RMSEA always meeting the Hu and Bentler (1999) limits. This is evidence that the structure of populist attitudes is the same across the countries and suggests cross-national consistency in the meaning of populism.

Turning to metric invariance, we find strong evidence that the scale metric is identical across countries. When equality restrictions are imposed on factor loadings, the model fit is still satisfactory $(\mathrm{CFI}=.966$; RMSEA $=.053)$. Moreover, the reduction in CFI and increase in RMSEA relative to the configural invariance model are well within the limits proposed by Chen (2007). Taken together, the second-order factor model of IPA exhibits metric invariance across the countries under investigation. Thus, the structure and factor loadings are invariant and an interpretation of correlations of this scale with other (invariantly measured) concepts across countries is therefore admissible.

The IPA items fare worse in terms of scalar invariance. Although the RMSEA of the scalar invariance model is still acceptable at .078, the CFI (.920) is insufficient. Additionally, the decrease in CFI relative to the metric invariance model is too high (-.046), while the increase in RMSEA (.025) also exceeds the Chen (2007) limits.

The lack of invariance is mostly due to the homogeneity items, as is evident from score tests. Those tests indicate how much the model fit would increase should a particular restriction, in this case on the measurement intercepts, be removed. Further, Nye and 
Drasgow (2011) suggest inspecting effect size indices to identify groups and items detrimental to measurement equality. Applying these methods, we identified one item (hom3) and one group (Sweden) that accounted for the bad fit of the scalar invariance model. Omitting Sweden and relaxing the constraint on hom3, the model fit increases to almost acceptable fit indices $(\mathrm{CFI}=.943 ; \mathrm{RMSEA}=.066)$.

While this does not fully resolve the problems with scalar invariance, a relaxation of all intercepts of the two items with the largest modification indices per factor (anti1 \& 3; sov2 $\& 4$; hom $1 \& 3)$ resulted in an acceptable model fit $(\mathrm{CFI}=.960 ; \mathrm{RMSEA}=.058)$ well within the limits defined by Chen (2007). We conclude that, albeit no complete scalar invariance was found, there is partial scalar invariance.

\section{Criterion Validity}

To test for criterion validity, we link the factor scores of IPA to left-right-orientation and voting intentions. In doing so, we reunite the invariant measurement with the unique political reality in each country. Not only are the parties, their positions, and their history specific to each country, we also have little reason to expect measurement invariance for the single-item measurement of self-disclosed left-right orientation. This means that countryspecific effects have to be considered when interpreting this validation.

For left-right orientation, we expected people at the extremes of the ideological spectrum to exhibit stronger populist attitudes, resulting in a quadratic relationship. This is especially the case in countries where populist parties at both ends of the spectrum exist. In countries with only right- or left-wing populism, the pattern may be more linear as we expect the political reality to be in line with the attitudes of the public. To capture this variation, we estimate hierarchical regressions with and without quadratic term, using countries as the second level and respondents as the first. 
As expected, the quadratic model $\left(R^{2} a d j=.0125 ; F(2,1648)=68.05\right.$, Online Appendix B) fits the data better than the linear model $\left(R_{a d j}^{2}=.0062 ; F(1,10649)=67.26\right)$, although right-wing populism is more prominent in the countries under investigation and citizens on the extreme right have higher IPA scores than those on the extreme left. Importantly, those in the middle of the left-right scale show lower populist attitudes compared to both extremes.

When we compute country-specific intercepts that take into account the empirical Bayes residuals, three distinctive patterns emerge. In France, Germany, the Netherlands, Sweden, and the United Kingdom, we observe the curvilinear relationship. It is particularly pronounced in the United Kingdom, with the extreme left and right scoring about the same on the IPA. In Austria, Italy, Poland, Switzerland, and the United States, this u-shape relationship is not found. Here, we observe a monotonic increase in expected IPA scores as we move from the left to the right. In Bulgaria, there is also no evidence of a curvilinear relationship. However, here the expected IPA score decreases monotonically as we move from the left to the right of the political orientations scale. These differences reflect the party system in the respective countries (Table 2).

In terms of voting intentions, we expected populist attitudes to be positively correlated with the intention to vote for populist parties and negatively with voting intentions for other parties. Table 4 shows the correlations between the IPA and vote intentions for populist parties. With few exceptions, we observe the correlations to be statistically significant and positive. The relation was found for parties on both ends of the political spectrum with support for the German Die Linke equally linked to populist attitudes as the French Front National. In some countries where several populist parties compete (Austria, Italy and Great Britain), however, not all voting preferences for populist parties were significantly associated 
with populist attitudes. One atypical case is the negative correlation between the IPA and the intention to vote for GERB in Bulgaria.

Table 5 shows that the IPA generally correlates significantly and negatively with vote intentions for non-populist parties. Only in one case is the sign reversed: voting for the Christian Democrats (CVP) in Switzerland. In all other cases of sign reversals, the correlations are not statistically significant. The results from the analyses of political orientations and vote intentions show that the IPA generally behaves as it should when confronted with the political realities of the countries under investigation, and exhibits criterion validity. The few exceptions will be discussed below.

\section{Conclusion}

In this study, we set out to systematically test the measurement invariance of populist attitudes in Western Democracies as measured in the three-dimensional and deductively derived inventory of populist attitudes (IPA, Schulz et al. 2017). By adhering to an etic perspective and guidelines offered for comparative research and measurement invariance (Davidov et al., 2014; Jowell, 1998; Byrne et al. 2009), we translated and tested the scale in eleven different countries, representing the five dominant cultures of Western Democracies.

We found that the scale exhibits configural and metric invariance in all countries under investigation. Consequently, the scale can be applied as a reliable measure in comparative research and the correlations of the latent variables with other concepts can be compared between countries. Scalar invariance, which is a prerequisite for the comparison of mean scores across countries (Steenkamp \& Baumgartner, 1998), was only partially achieved. We suspect that answers to the most problematic item for scalar invariance (hom 3: "Ordinary people share the same values and interests") depends on the perceived pluralism within countries and may bias the measurement in some countries. Accordingly, comparisons of 
mean values across countries should be done with reservation. We especially advise caution when applying the scale in Sweden as it reduced the model fit due to very low scores on the dimensions of popular sovereignty and homogeneity. Apart from these reservations, however, the results indicate that the scale reliably taps into the same three-dimensional concept of core populist attitudes in all countries. The three dimensions, thereby, are not genuinely populist in isolation, as individuals may be either critical toward the elite, proud of their people, or in favor of direct democracy without being populist. It is the common variance of these three dimensions, we consider a measurement for populism.

To assess the external validity of the instrument, the measurement was analyzed in the context of the current political realities in the eleven countries by linking populist attitudes to self-reported left-right orientation and voting propensity. As expected, we found that populist attitudes were linked to both left- and right-wing political orientation. The curvilinear relationship between populism and orientation indicates that the IPA is suited to assess populism regardless of other political ideologies. In this study, the lowest values for populism were found for moderate left respondents, while there is a general tendency toward right-wing populism. This may be due to the selection of cases with many of the countries having strong right-wing populist parties but only few strong left-wing populist forces (see Table 2).

A further indication for a valid measurement of populism lies in the correlation of populist ideology and voting intention. With few exceptions, individuals with stronger populist attitudes were more supportive for populist parties and less supportive for nonpopulist parties. Only for three of the investigated 70 parties is this pattern contradicted.

First, the GERB in Bulgaria is less supported by populist individuals in spite of this party having been identified as a populist movement by van Kessel (2015). A reason for this deviation may lie in the change this party has undergone since its founding in 2009 and has 
become part of the political elite by the time of our survey in 2015. Second, the National Front for Salvation of Bulgaria (NFSB) received more support from voters with populist ideology in spite of not being commonly portrayed as a populist party. The reason for this relation may lie in the history of this young party which formed from a fraction of the populist Attack Party (PA) in 2011 and its voter base largely consists of former PA voters. Third, we found a positive correlation between populist ideology and support for the Christian Democratic Party (CVP) in Switzerland, although this party is not commonly considered populist. A possible reason for this finding is the shift in communication of the CVP in the early 2000s when it started using stronger populist language than any other party in political debates (Cranmer, 2011, p. 299) without adapting populist ideology in their party manifesto. This shift in self-presentation may have attracted voters with populist attitudes.

In sum, the deviations from the expected relations between populist attitudes, voter support, and left-right-orientation are plausible and do not question the external validity of the IPA. It has to be noted, however, that the association of populist attitudes and voting propensity is generally weak to moderate. This is most likely due to the fact that the measurements tap into different concepts. The IPA measures a highly abstract general concept of populist attitudes which is invariant across space and time but hardly ever manifests in its pure form. Voting propensity, on the other hand, measures the support for actual political actors with clearly expressed positions on a multitude of issues, with (un-)likable leading candidates, and with their own histories of scandals and victories. Also, asking for voting propensities only makes sense if voters are used to reflecting their probability of voting for parties instead of candidates. It is, therefore, to be expected that populist attitudes only explain a fraction of the support for a real party. Even more so, the overall consistent pattern of an association between populist attitudes and voting propensity points toward a high 
external validity of the IPA. The scale may therefore be considered to be an appropriate measurement of populist attitudes in the eleven countries under investigation.

While this study is limited in its scope by the deliberate restriction on Western Democracies and the application to an online access panel, we consider it to be a first and important step in establishing cross-nationally valid measurement approaches to populist attitudes. Furthermore, as the scale is deduced from the minimal definition of thin populist ideology and translated from an etic perspective, we are confident that the scale measures the essence of populism, regardless of culture and current political situations and is applicable to other cultural contexts (e.g. southern American or Asian) as well.

Future research may build on this work by adding adjunct attitudes, such as exclusionism or nationalism to capture current right-wing populist ideology and align the measurement with the political reality in specific countries. Also, since measurement invariance has been successfully established, future research may use this scale for more indepth analyses of cross-cultural differences in populist reality. We do not propose that this scale is the single and best solution to measure populism, but propose it as a valid option cross-national populism research. 


\section{References}

Albertazzi, D., \& McDonnell, D. (2008a). Introduction: The sceptre and the spectre. In D. Albertazzi \& D. McDonnell (Eds.), Twenty-first century populism: The spectre of western European democracy (pp. 1-11). Basingstoke: Palgrave

Akkerman, A., Mudde, C., \& Zaslove, A. (2014). How populist are the people? Measuring populist attitudes in voters. Comparative Political Studies, 47(9), 1324-1353. doi:10.1177/0010414013512600

Bakker, B. N., Rooduijn, M., \& Schumacher, G. (2015). The psychological roots of populist voting: Evidence from the United States, the Netherlands and Germany. European Journal of Political Research, n/a-n/a. doi:10.1111/1475-6765.12121

Barr, R. R. (2009). Populists, outsiders and anti-establishment politics. Party Politics, 15(1), $29-48$.

Byrne, B. M., Shavelson, R. J., \& Muthén, B. (1989). Testing for the equivalence of factor covariance and mean structures: The issue of partial measurement invariance. Psychological Bulletin, 105(3), 456-466. doi:10.1037/0033-2909.105.3.456

Chen, F. F. (2007). Sensitivity of goodness of fit indexes to lack of measurement invariance. Structural Equation Modeling: A Multidisciplinary Journal, 14(3), 464-504. doi:10.1080/10705510701301834

Cranmer, M. (2011). Populist communication and publicity: An empirical study of contextual differences in Switzerland. Swiss Political Science Review, 17(3), 286-307. doi:10.1111/j.1662-6370.2011.02019.x

Davidov, E. (2009). Measurement equivalence of nationalism and constructive patriotism in the ISSP: 34 countries in a comparative perspective. Political Analysis, 17(01), 64-82. doi:10.1093/pan/mpn014 
Davidov, E., Cieciuch, J., Meuleman, B., Schmidt, P., Algesheimer, R., \& Hausherr, M. (2015). The comparability of measurements of attitudes toward immigration in the European Social Survey. Public Opinion Quarterly, 79(S1), 244-266. doi:10.1093/poq/nfv008

Ernst, N., Engesser, S., Büchel, F., Blassnig, S., \& Esser, F. (2017). Extreme parties and populism: An analysis of Facebook and Twitter across six countries. Information, Communication \& Society, 20(9), 1347-1364. doi:10.1080/1369118X.2017.1329333

Hameleers, M., Bos, L., \& de Vreese, C. H. (2017). The appeal of media populism: The media preferences of citizens with populist attitudes. Mass Communication and Society, 20(4), 481-504. doi:10.1080/15205436.2017.1291817

Harkness, J. A., Villar, A., \& Edwards, B. (2010). Translation, adaption, and design. In J. A. Harkness, M. Braun, B. Edwards, T. P. Johnson, L. E. Lyberg, P. P. Mohler,. . . T. W. Smith (Eds.), Wiley series in survey methodology. Survey methods in multinational, multiregional and multicultural contexts (pp. 117-140). Hoboken, N.J: J. Wiley.

Hawkins, K. A., Riding, S., \& Mudde, C. (2012). Measuring populist attitudes. C\&M Working Paper \#55.

Hawkins, K. A., \& Rovira Kaltwasser, C. (2017). What the (Ideational) Study of populism can teach us, and what it can't. Swiss Political Science Review, 23(4), 526-542. doi:10.1111/spsr.12281

Hu, L., \& Bentler, P. M. (1999). Cutoff criteria for fit indexes in covariance structure analysis: Conventional criteria versus new alternatives. Structural Equation Modeling: A Multidisciplinary Journal, 6(1), 1-55. doi:10.1080/10705519909540118

Jowell, R. (1998). How comparative is comparative research? American Behavioral Scientist, 22(2), 168-177. 
Littvay, L., \& Castanho Silva, B. (2016, September). Presenting a cross nationally validated populist attitudes scale. ECPR General Conference, Prague, CZ.

Manucci, L., \& Weber, E. (2017). Why the big picture matters: political and media populism in Western Europe since the 1970s. Swiss Political Science Review, 23(4), 313-334. doi:10.1111/spsr.12267

Mead, W. R. (2011). The Tea Party and American foreign policy: What populism means for globalism. Foreign Affairs, 90(2), 28-44.

Mudde, C. (2004). The populist zeitgeist. Government and Opposition, 39(4), 542-563. doi:10.1111/j.1477-7053.2004.00135.x

Müller, P., Schemer, C., Wettstein, M., Schulz, A., Wirz, D. S., Engesser, S., \& Wirth, W. (2017). The polarizing impact of news coverage on populist attitudes in the public:

Evidence from a panel study in four European democracies. Journal of Communication, 67(6), 968-992. doi:10.1111/jcom.12337

Nye, C. D., \& Drasgow, F. (2010). Assessing goodness of fit: Simple rules of thumb simply do not work. Organizational Research Methods, 14(3), 548-570. doi:10.1177/1094428110368562

Oliver, J. E., and Wendy M. Rahn. 2016. "Rise of the Trumpenvolk." The Annals of the American Academy of Political and Social Science 667 (1): 189-206.

Piurko, Y., Schwartz, S. H., \& Davidov, E. (2011). Basic personal values and the meaning of left-right political orientations in 20 countries. Political Psychology, 32(4), 537-561. doi:10.1111/j.1467-9221.2011.00828.x

Rooduijn, M. (2014). Vox populismus: A populist radical right attitude among the public? Nations and Nationalism, 20(1), 80-92. doi:10.1111/nana.12054 
Rooduijn, M. (2017). What unites the voter bases of populist parties? Comparing the electorates of 15 populist parties. European Political Science Review, 20, 1-18. doi:10.1017/S1755773917000145

Rooduijn, M., de Lange, S. L., \& van der Brug, W. (2014). A populist zeitgeist? Programmatic contagion by populist parties in Western Europe. Party Politics, 20(4), 563575. doi:10.1177/1354068811436065

Rosseel, Y. (2012). lavaan: An R package for structural equation modeling. Journal of Statistical Software, 48(2). Retrieved from https://www.jstatsoft.org/article/view/v048i02

Rovira Kaltwasser, C., \& Hawkins, K. A. (2014, May). The populist spectre in contemporary Chile. XXXII International Congress of the Latin American Studies Association, Chicago.

Satorra, A., \& Bentler, P. M. (2001). A scaled difference chi-square test statistic for moment structure analysis. Psychometrika, 66(4), 507-514.

Schulz, A. (2018). Where populist citizens get the news: An investigation of news audience polarization along populist attitudes in 11 countries. Communication Monographs, 67, 124. doi:10.1080/03637751.2018.1508876

Schulz, A., Müller, P., Schemer, C., Wirz, D. S., Wettstein, M., \& Wirth, W. (2017). Measuring populist attitudes on three dimensions. International Journal of Public Opinion Research 30(2), 316-326. doi:10.1093/ijpor/edw037

Schulz, A., Wirth, W., \& Müller, P. (2017). We are the people and you are fake news: A social identity approach to populist citizens' false consensus and hostile media perceptions. Communication Research, 12, doi:10.1177/0093650218794854

Stanley, B. (2011). Populism, nationalism, or national populism? An analysis of Slovak voting behaviour at the 2010 parliamentary election. Communist and Post-Communist Studies, 44(4), 257-270. doi:10.1016/j.postcomstud.2011.10.005 
Stavrakakis, Y., Andreadis, I., \& Katsambekis, G. (2016). A new populism index at work: Identifying populist candidates and parties in the contemporary Greek context. European Politics and Society, 1-19. doi:10.1080/23745118.2016.1261434

Steenkamp, J. E. M., \& Baumgartner, H. (1998). Assessing measurement invariance in crossnational consumer research. Journal of Consumer Research, 25(1), 78-107. doi:10.1086/209528

Taggart, P. (2000). Populism. Buckingham: Open University Press.

Van Hauwaert, S. M., \& van Kessel, S. (2017). Beyond protest and discontent: A crossnational analysis of the effect of populist attitudes and issue positions on populist party support. European Journal of Political Research, 47(9), 1324. doi:10.1111/14756765.12216

Van Kessel, S. (2015). Populist parties in Europe: Agents of discontent? Basingstoke, New York: Palgrave Macmillan.

Wirth, W., Esser, F., Wettstein, M., Engesser, S., Wirz, D. S., Schulz, A.,. . Schemer, C. (2016). The appeal of populist ideas, strategies, and styles: A theoretical model and research design for analyzing populist political communication: http://www.nccrdemocracy.uzh.ch/publications/workingpaper/pdf/wp88.pdf

Wirth, W., \& Kolb, S. (2012). Securing equivalence: Problems and solutions. In F. Esser \& T. Hanitzsch (Eds.), Handbook of comparative communication research (pp. 469-485). New York, NY: Routledge

Wirz, D. S., Wettstein, M., Schulz, A., Müller, P., Schemer, C., Ernst, N., . . Wirth, W. (2018). The effects of right-wing populist communication on emotions and cognitions toward immigrants. The International Journal of Press/Politics, 38, doi:10.1177/1940161218788956 